Reportaje publicado en Cahiers du cinéma

( $N^{\circ} 403$, enero de 1988)

\section{Raymond Depardon. La conciencia del cineasta}

CAHIERS: ¿Cómo se le ocurrió filmar su último film Urgences (Urgencias)? ${ }^{(1)}$

DEPARDON: Al principio quería hacer un film sobre la justicia. Fui a ver a los responsables de ese extraño lugar que es el Palacio de Justicia, una especie de Vaticano de París. La continuación lógica de Faits divers (Policiales), ${ }^{(2)}$ era forzosamente la justicia. Mi idea era filmar el juicio de un delito menor, que se resuelve rápidamente, tomando al personaje desde su detención hasta su presentación inmediata frente al juez. Al principio autorizaron la filmación pero al cabo de un año hubo un cambio en la Fiscalía y finalmente las autoridades judiciales se retractaron. Como tenía el dinero para hacer el film -era la primera vez que tenía montada la producción antes de filmar- propuse otro tema: el servicio de urgencias psiquiátricas en el Hospital de París. En realidad, ese es uno de los corredores, el otro es la justicia, donde aterrizan los que piden auxilio. Es la otra respuesta de las instituciones a una situación de urgencia.

CAHIERS: ¿Por qué le impidieron filmar en el Palacio de Justicia?

DEPARDON: Invocaron el secreto del sumario. Es curioso porque todos esos pequeños delitos que queríamos filmar hubiesen estado resueltos cuando el film hubiese estado terminado. Había en todo caso menos violaciones al secreto del sumario que en los libros de memorias de ex policías, abogados o jueces que se publican frecuentemente.

CAHIERS: ¿TUvo tiempo para preparar Urgences?
DEPARDON: Directamente, no lo preparé; se hizo de una manera muy improvisada, y ahí yo tuve por segunda vez (la primera vez fue en el film sobre Giscard d'Estaing) ${ }^{(3)}$ a una sonidista: Claudine Nougaret. Ella hizo el sonido del film, lo que modificó mi manera de filmar.

CAHIERS: ¿Usted tiene un método para preparar sus films, o actúa de manera empírica, según cada film?

DEPARDON: Existen dos tipos de films. Algunos son muy preparados, como Reporters (Reporteros) ${ }^{(4)} \mathrm{O}$ San Clemente, ${ }^{(5)}$ incluso Numero zero. ${ }^{(6)}$ Una parte mía retoma el camino del fotógrafo de prensa pero con un nuevo instrumento, la cámara cinematográfica, como si tuviera que saldar cuentas con ese testigo un poco pasivo que es el fotógrafo. Por ejemplo, había hecho muchas fotos en hospitales psiquiátricos antes de filmar San Clemente. Para otros films como Faits divers o Urgences se parte de algo más interior. Es un mundo que conozco menos, pero el tema lo tenía en la cabeza desde hacía mucho tiempo: quería hacer un film sobre algo que tuviera que ver con el psicoanálisis, un frente a frente entre alguien que hable y alguien que escuche, algo cercano a una confidencia. No hice ninguna fotografía de los lugares antes de la filmación para preservar una mirada virgen.

CAHIERS: Cuando usted llegó ¿se puso a filmar, sin conversaciones previas?

DEPARDON: El Jefe del Servicio de Urgencias, doctor Grivois, intentó más bien disuadirnos de filmar, diciéndonos que no sucedía nada espectacular. Le 
expliqué que justamente lo que buscaba era gente como usted o como yo que pasan por un momento difícil y que no aguantan más. Cuanto más "normal" era esa gente más nos interesaba. Las condiciones de filmación fueron muy particulares y a veces había que filmar inmediatamente. Me instalaba y no me movía, hacía planos fijos y me mantenía a distancia.

CAHIERS: ¿Cómo determina la "buena" distancia respecto de lo que filma?

DEPARDON: El hecho de haber filmado Empty Quarter - Une femme en Afrique (Una mujer en África) ${ }^{(7)}$ modificó totalmente mi manera de trabajar. Hoy dejo que la gente salga de cuadro, y me quedo en los que no se mueven, como si ya existiera una puesta en escena. Además, al no tener el micrófono adosado a la cámara puedo tener la distancia visual necesaria, contrariamente a mis films anteriores. El trabajo de Claudine Nougaret da al sonido la calidad de un film de ficción, y yo lo hice con mi experiencia de documentalista, poniendo a la gente en su contexto, pero sin hacer demasiados primeros planos, como se suele hacer en los reportajes, respetando así el frente a frente. Me parece que la experiencia de Empty Quarter modificó mi enfoque de las cosas. Cuanto más se escucha menos hace falta moverse. Yo escuchaba el sonido de la toma y me daba cuenta, gracias a lo que escuchaba, de lo interesante que era. Era como el "primer espectador" y aun en los momentos en que no pasaba nada me daba cuenta de que no tenía que moverme. Al encuadrar de una cierta manera yo afirmaba un principio básico. Por ejemplo, al filmar al psiquiatra y al enfermo, si el psiquiatra se levantaba, yo no me movía, como si todo hubiese estado preparado de antemano. Hace algunos años yo hubiese cambiado el encuadre siguiendo a quien se movía. Si quisiera resumir mi evolución de documentalista diría que la parte reportaje es menor. El cine con sonido directo tiene más de 30 años y no estamos más en el cinéma-verité. Ya no se puede hacer como en los años 60. Hay que mostrar las cosas, sin dramatizar, y podemos hacerlo porque hay nuevas películas y el sonido tiene más calidad.

CAHIERS: ¿Veía los campeones a medida que avanzaba la filmación?

DEPARDON: No. Es un residuo de mi experiencia de fotógrafo, lo que por otra parte molestó mucho a la sonidista. Pienso que la emoción en filmación o se la tiene o no se la tiene. Cuando uno es testigo de algo, eso puede aparecer. Y además tengo la impresión de ser así más honesto. Si hubiésemos visto las tomas ya filmadas uno habría vuelto frotándose las manos y diciendo: "Hay buenas cosas...". Eso me parece horrible; ya se es suficientemente vampiro. El no mirar los campeones nos imponía una cierta modestia frente a la gente que filmábamos, que no transformábamos en fenómenos de feria, o en actores. Si existe un progreso en mi manera de filmar está en mi conciencia de la toma. De esta forma se puede ser un poco menos un "mirón".

CAHIERS: Wiseman ${ }^{(8)}$ explicaba recientemente en la Cinemateca que él hacía sus films en el montaje. ¿Usted está de acuerdo? 
DEPARDON: Siempre dije que no. Respeto mucho a los montajistas de mis films pero incluso ellos le dirán que no se puede inventar una escena que no existe. El montaje lleva tiempo, sobre todo por la reflexión que el film impone. En Urgences y en San Clemente es sobre todo una cuestión de selección: había que elegir entre dos o tres planos secuencias de 4 ó 5 minutos, pero no tomando un pedazo de cada uno, sino uno u otro; y para hacer esto hay que pensar mucho. Pero un film no se hace en la etapa del montaje. Me gusta trabajar con el montajista sobre todo para tener a alguien frente a mí, para poder confrontarme con alguien distinto.

CAHIERS: Tanto en el documental como en la ficción la cuestión del ritmo es esencial. ¿Cómo encuentra el ritmo de un film?

DEPARDON: Me parece que el ritmo se impone a partir del material bruto. Para mí un gran montajista parte de cierto material inicial y respeta su extensión, pero eliminando toda repetición. Por ejemplo, había que elegir el testimonio de un toxicómano entre los numerosos testimonios de toxicómanos que pasaban por el Servicio de Urgencias.

CAHIERS: Usted dijo al comienzo de este reportaje que Urgences era el primero de sus films con una producción montada antes de hacerlo. ¿Qué pasa en los otros casos?

DEPARDON: Normalmente, para los films más ricos, uno tiene un adelanto de la televisión que no alcanza para financiar el film (fue el caso de Reporters). San
Clemente fue producida por mí y mi socia, Pascale Dauman. Mis películas son difícilmente exportables. Un film cuesta un millón de francos, cuanto menos. Urgences fue producido por el Canal I de Televisión (TFI) y tuvo el apoyo del Fondo de Apoyo Audiovisual (organismo oficial).

CAHIERS: ¿A usted le parece que ha evolucionado la imagen del documental en la televisión?

DEPARDON: Temo que se quieran hacer cosas demasiado cortas, demasiado puntuales, para no aburrir a la gente. Con el pretexto de que superamos el período experimental de los años 60 y el período político de los 70 , se abandona el género documental como si se lo hubiese agotado. Los ejecutivos de los canales de televisión tienen miedo al riesgo. Propuse hacer un documental con una sobrina mía que pasaba el examen del bachillerato, y ellos pensaban que 26 minutos alcanzaban para hacer eso. Estoy persuadido de que hubiera sido necesario un film más largo. El canal 7 pide proyectos de films sobre escritores, pero ahí también establecen el tope de los 26 minutos. Es necesario no solamente tiempo para el film, sino también para la filmación; nosotros estuvimos dos meses filmando en el Hospital de París. No se puede hacer un film de 26 minutos filmando una semana solamente. Esa es, sin embargo, la duración media de las filmaciones en la televisión actualmente. La televisión no ha reflexionado sobre su tiempo. Felizmente, a veces, se produce el milagro, y tenemos 20 segundos en la fiesta de l'Humanité con un tipo que habla realmente como un parisino, y es una bocanada de aire fresco; pero eso no alcanza. 
CAHIERS: ¿A usted le parece que hoy, haciendo documentales, se deben abordar otros temas?

DEPARDON: Ya se terminó un poco con el género "Las naranjas de California", y lo mismo con las comisarías... Se pueden tratar otras cosas, además de los márgenes, las clases sociales o las instituciones; se puede volver a tratar a los personajes. No ir a buscar a los campesinos lejanos, filmar las cosas de hoy. Gente como Flaherty o Rosellini estarían encantados con el material técnico actual. Existe, entre la pesada ficción y una forma de documental un poco anacrónica, todo un campo para explorar.

\section{Notas}

Urgences, documental realizado en 1987, $1 \mathrm{~h} 44 \mathrm{~min}$. Faits divers, film realizado en 1983, $1 \mathrm{~h} 48 \mathrm{~min}$.

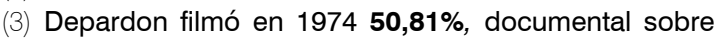
la campaña del candidato y luego presidente Giscard d'Estaing, quien prohibió la difusión del film durante 28 años. En 2002 se estrenó con el título 1974 Une partie de campagne.

(4) Reporters, 1980, 1 h 30 min.

(5) San Clemente, 1980, 1 h 30 min. Documental sobre un hospital psiquiátrico italiano.

(6) Numero zero, 1977, 1 h 30 min. Documental sobre el diario parisino Le Matin.

(7) Primer film de ficción de Depardon, 1985, 1 h 25 min.

(8) Frederick Wiseman, documentalista estadounidense actual. 